\title{
Gestão de marcas na estratégia de internacionalização de empresas: um estudo exploratório no Banco Itaú
}

Trademarks management in the strategy of internationalization of companies: an exploratory study in Banco Itaú

Gestión de marcas en la estrategia de internacionalización de empresas: un estudio exploratorio en el Banco Itaú

(9) Daniela Motta Romeiro Khauaja

- Doutora e Mestre em Administração de Empresas pela Faculdade de Economia, Administração e Contabilidade da Universidade de São Paulo (FEA-USP)

- MBA em Marketing pela Western International University, de Londres

- Bacharel em Publicidade e Propaganda pela Pontifícia Universidade Católica do Rio de Janeiro (PUC-RJ)

- Coordenadora da área de Marketing da Pós-Graduação da Escola Superior de Propaganda e Marketing (ESPM-SP)

- Tem mais de quinze anos de experiência como executiva na área de Marketing

- Presidente do Comitê de Marketing da Câmara Americana de Comércio de São Paulo (Amcham-SP) - 2014-2015

- Diretora de Conteúdo do G100 ${ }^{\circledR}$ Marketing \& Business

- E-mail:dkhauaja@espm.br 


\section{Resumo}

O objetivo geral deste artigo é analisar o processo de construção e gestão de marcas de empresas brasileiras multinacionais no âmbito da estratégia de internacionalização. 0 investimento na gestão de marcas é uma forma eficaz de diferenciar as ofertas brasileiras no exterior, gerando valor agregado. 0 estudo justifica-se, podendo servir como conscientização e benchmarking para empresários brasileiros nesse processo. Realizou-se uma pesquisa exploratória e qualitativa. 0 Banco Itaú foi escolhido como objeto de estudo pela importância do setor financeiro, pelo alto investimento realizado na marca e pelo fato de já ter sido considerada a marca mais valiosa do país.

\section{PALAVRAS-CHAVE: INTERNACIONALIZAÇÃO・GESTÃO DE MARCAS・MULTINACIONAIS BRASILEIRAS.}

\section{Abstract}

The general objective of this article is of analyzing the process of construction and management of trademarks of multinational Brazilian companies within the scope of the internationalization strategy. Investment in the management of trademarks is an efficacious way of differentiating the Brazilian offerings abroad, generating added value. The study is justified and can serve in this process as conscientiousness and benchmarking for Brazilian businesspeople. An exploratory and qualitative research was conducted. Banco Itaú, a Brazilian private bank, was chosen as the subject-matter of the study due to the importance of the financial sector, to the substantial investments made in the trademark and to the fact that it has already been considered to be the most valuable trademark in the country.

\section{KEYWORDS: INTERNATIONALIZATION・TRADEMARKS MANAGEMENT・BRAZILIAN MULTINATIONALS.}

\section{Resumen}

El objetivo general de este artículo es analizar el proceso de construcción y gestión de marcas de empresas brasileras multinacionales en el ámbito de la estrategia de internacionalización. La inversión en la gestión de marcas es una forma eficaz de diferenciar las ofertas brasileras en el exterior, generando valor agregado. El estudio se justifica, pudiendo servir como concientización y benchmarking para empresarios brasileros en ese proceso. Se realizó una investigación exploratoria y cualitativa. El Banco Itaú fue escogido como objeto de estudio por la importancia del sector financiero, por la alta inversión realizada en la marca y por el hecho de ya haber sido considerada la marca más valiosa del país. 
$\mathrm{N}$

este estudo, combinam-se dois temas relevantes e atuais: a internacionalização de empresas e a gestão de marcas. A internacionalização dos negócios e o advento das empresas multinacionais não são fenômenos novos, mas a participação de empresas procedentes de países em desenvolvimento, como o Brasil, no contexto global ainda é um acontecimento relativamente recente (Gião et al., 2008).

Por meio das marcas, as empresas buscam identificar e diferenciar suas ofertas, tornando-as mais atraentes para seus clientes potenciais. Estes, por sua vez, consomem marcas não apenas para atender necessidades e desejos, mas também para expressar sua identidade e fazer parte de comunidades. As marcas evoluíram da fase industrial, quando sua função era nomear produtos, para a semiótica, baseada em serviços e cujos objetivos são propor um projeto de sentido para o próprio ato de consumir e estabelecer uma relação com seus clientes.

A fim de crescer e obter resultados mais positivos, muitas empresas decidem competir no mercado internacional, transformando marcas locais em globais ou criando novas marcas globais. A marca global é aquela que transcende suas origens geográficas e culturais para desenvolver forte relacionamento com consumidores em diferentes países e com diferentes culturas (Hollis, 2008).

A necessidade de inserção no mercado global para o crescimento econômico do país já é quase um consenso no Brasil e cresce o número de empresas que buscam essa inserção de forma estruturada. Para competir globalmente, é premente que as ofertas brasileiras busquem uma diferenciação, o que pode ser alcançado por meio da construção e da gestão de marcas.

O presente estudo busca analisar o processo de construção e gestão de marcas de empresas brasileiras no âmbito da estratégia de internacionalização. Ele tem como objetivo formular conhecimento novo acerca da realidade investigada: a construção e a gestão de marcas brasileiras no exterior. Dado que o investimento na gestão de marcas é uma forma eficaz de diferenciar as ofertas brasileiras no exterior, gerando valor agregado, o estudo justifica-se porque a análise dos fatores críticos para a gestão de marcas de empresas que se internacionalizaram com sucesso pode servir como conscientização e benchmarking para empresários brasileiros nesse processo. 0 conhecimento gerado pode ser facilmente aplicado por empresas brasileiras em processos de internacionalização e pode colaborar para que, num futuro próximo, haja muitos exemplos de sucesso de empresas multinacionais brasileiras.

Na primeira parte do artigo, explicitam-se o problema e os objetivos da pesquisa, para em seguida fazer uma revisão bibliográfica, abordando a gestão de marcas globais; na segunda parte esclarece-se o procedimento metodológico da pesquisa de campo; na terceira parte, apresenta-se o resultado da pesquisa empírica; e, por fim, se expõem as considerações finais e as limitações do estudo, bem como recomendações para estudos futuros.

\section{PROBLEMA E OBJETIVOS DA PESQUISA}

Ao analisar pesquisas que tratam de estatísticas e rankings relacionados à internacionalização, é possível perceber que o Brasil conta com poucos exemplos de empresas internacionais, porém esses são de muito sucesso. Partindo desse paradoxo, o objetivo geral deste artigo é descrever os fatores críticos para a construção e a gestão de marcas de empresas brasileiras multinacionais no âmbito da estratégia de internacionalização. Para a consecução desse objetivo, devem ser analisados os seguintes elementos: 
a) o processo de internacionalização da empresa, incluindo as motivações para a internacionalização, os modos de entrada selecionados e as dificuldades encontradas nesse processo;

b) o modelo mental dos dirigentes, isto é, sua capacidade de desenvolver visão global do mundo e de ter pensamento de longo prazo;

c) as bases para a internacionalização das empresas (aquisição ou desenvolvimento de recursos internos e externos);

d) a utilização de marcas na estratégia de internacionalização da empresa e o modo como elas foram construídas e são gerenciadas no exterior;

e) o modo como a empresa gerencia o composto de marketing (produto, preço, comunicação e distribuição);

f) a forma como a empresa criou infraestrutura para a gestão das marcas no exterior.

\section{REVISÃO BIBLIOGRÁFICA}

No que tange à construção de marcas globais, David Aaker e Erik Joachimsthaler (1999) declararam tratar-se de marcas cujos posicionamentos, estratégia de comunicação e personalidade são, na maioria dos aspectos, os mesmos em diferentes países e mercados. Eles afirmam que é necessário desenvolver marcas sólidas nos vários mercados por meio de uma liderança de marca global, o que inclui utilizar estruturas organizacionais, processos e culturas para alocar globalmente os recursos de construção da marca criando sinergias globais, além de desenvolver uma estratégia global de marca que coordene e potencialize as estratégias de cada país. Mas eles também apontam para o desafio de encontrar um equilíbrio entre potencializar a marca globalmente e respeitar as diferenças locais, tema recorrente na discussão sobre o marketing global.

Marcas locais são diferenciadas de marcas internacionais por Isabelle Schuiling e Jean-Noël Kapferer (2004), para os quais marcas locais são as que existem em um país ou são limitadas a uma área geográfica, podendo pertencer a uma empresa local ou global. Já as marcas internacionais são aquelas que possuem elementos da estratégia ou do composto de marketing globalizados. Citando Theodore Levitt (1983), eles ponderam que, de forma mais radical, marcas globais são definidas como marcas que utilizam a mesma estratégia de marketing e o mesmo composto de marketing em todos os mercados-alvo.

Já Paul Temporal (2001) tentou ir além e diferenciar os conceitos de marca internacional e de marca global, embora isso pareça um tanto confuso. Para o autor, a marca global é a que está presente em quase todos os países do mundo, utiliza o mesmo nome, tem os mesmos valores e o mesmo posicionamento em todos os países. Nesse caso, seus produtos têm apelo universal e são direcionados a segmentos-alvo globais (por exemplo, jovens executivos). Em oposição, as marcas internacionais são aquelas que estão presentes em poucos países, utilizam nomes diferentes, fazem adaptações em seus posicionamentos e em suas ofertas. De acordo com os critérios do autor, possivelmente apenas uma meia dúzia de marcas poderia ser considerada global de fato.

A simplificação do conceito de que "uma marca é global quando é conhecida no mundo inteiro" é questionada por Kapferer (2004, p. 13). Ele defende que privilegiar a unidade mais do que a diversidade é um modelo de gestão governado pelos custos 
e pela busca de eficiência. Embora a redução dos custos seja obviamente importante, é preciso reconhecer que as diferenças culturais ainda existem. Assim, o autor acredita que a marca tem três elementos globalizáveis: um "multissinal" (nome, identidade gráfica ou símbolo); um produto (bem ou serviço) e um posicionamento (promessa de qualidade). E existem várias combinações de globalização entre esses três elementos.

Reconhecendo que a globalização da economia mundial aumentou a complexidade da gestão internacional de marcas, 0 Journal of Brand Management teve, em 2005, uma edição especial sobre marcas globais, a qual reúne uma série de artigos que aqui serão abordados resumidamente.

Kapferer (2005) continuou atacando a padronização total de marcas globais. Ele cunhou o termo "pós-marca global", isto é, a marca que não adere totalmente ao modelo de globalização total, mas sim a uma "globalização seletiva", adotando um modelo híbrido entre globalização e localização (ou ao menos regionalização). Já Insa Matthiesen e lan Phau (2005) trataram da globalização de marcas de luxo, mais especificamente da marca Hugo Boss e de sua incursão no mercado australiano, tendo concluído que, embora a empresa tenha a intenção de adotar uma estratégia global para sua marca, há diferenças de imagem da marca entre os países.

Essa é justamente a dificuldade de uma marca que decide adotar uma estratégia global única quando já está na fase de maturidade, ou seja, não no momento do lançamento. Unificar estratégias já existentes é bastante problemático, pois os consumidores já possuem suas imagens formadas da marca e nem sempre tais imagens estão alinhadas com a identidade global. Por isso, é bastante produtivo pensar globalmente na marca desde o seu lançamento.

Sicco van Gelder (2005) definiu o que chamou de "novos imperativos para a gestão de marcas globais": estratégia, criatividade e liderança, defendendo que a combinação dos três é a chave para o sucesso das marcas globais, mas que a interação entre eles pode mudar em diferentes mercados. 0 autor definiu uma marca global sólida como aquela que oferece um valor excepcional aos seus diversos públicos de interesse, que moram em países muito diferentes, sob circunstâncias diferentes, com culturas diferentes e, frequentemente, com necessidades diferentes.

Como símbolos da cultura popular, o significado atribuído às marcas depende do contexto cultural em que elas são comercializadas (Hatch; Rubin, 2006). Contrariando as ideias de Levitt (1983), Saikat Banerjee (2008) defendeu a necessidade de integrar a marca a diferentes culturas. 0 autor defende que a marca pode ser bem-sucedida globalmente se respeitar diferentes valores culturais. Para eliminar as lacunas entre a herança da marca e a herança cultural, o autor propõe uma estratégia que se refere a decisões tomadas de acordo com a força ou a fraqueza da herança cultural e da herança da marca:

a) se ambas forem fracas ou se a herança cultural for fraca e a marca forte, a empresa deve construir e gerenciar a marca;

b) se ambas forem fortes, a empresa deve compreender as barreiras culturais e buscar brechas para fazer uma correspondência entre a marca e a cultura;

c) sea herança cultural for forte e a da marca for fraca, a empresa deve assimilar a cultura local para que a marca tenha aceitação. 
A fim de realizar seu estudo, Banerjee (2008) considerou o mercado indiano, mas T. C. Melewar et al. (2004), que consideraram o mercado chinês, também defenderam a necessidade de adaptar a marca à cultura local, o que passa por adaptar a própria cultura organizacional, compreender profundamente a cultura local e estar preparado para mudanças constantes no mercado, quando se estiver comercializando em países em desenvolvimento. Melewar et al. (2006) puderam reforçar isso quando analisaram a entrada da Danone na China, que foi um fracasso até que os executivos compreenderam a necessidade de adaptar os posicionamentos das marcas nas três categorias de atuação: lácteos, biscoitos e bebidas.

Há outros autores que também chamam a atenção para a questão da cultura. Bill Ramsay (2003), que analisou marcas globais no setor de comida industrializada, constatou que há maior dificuldade em tornar globais as marcas desse setor, uma vez que ele sofre fortes influências culturais. De fato, os hábitos alimentares mudam muito de um país para outro, como também constatou Barry Holden (2006), quando tentou lançar as marcas da Kraft Foods no mercado chinês. Ela relatou que, na China, a maioria das pessoas não tem forno em casa, o que dificulta a venda de produtos como pizzas prontas.

Holden (2006) chegou à conclusão de que, para lançar uma marca global, é preciso avaliar se ela atende às necessidades dos consumidores globais, se pode ser adaptada às diferenças de comportamento alimentar e renda de culturas diferentes e se a magnitude da oportunidade compensa os desafios. Para a autora, "um dos maiores desafios na construção de marcas globais é o balanceamento das melhores práticas de branding local e global. A meta é complementar a padronização global com a customização local" (Holden, 2006, p. 288). Dessa forma, ela recomenda que a marca (identidade e posicionamento) e 0 produto (qualidade e características principais) sejam globais e que o preço, a distribuição e a comunicação integrada sejam adaptados às necessidades locais.

Como é possível verificar, Ramsay (2003) e Holden (2006) lançaram luz sobre o perigo de generalizar a análise acerca das marcas globais, dado que cada setor de atuação tem suas peculiaridades. No setor de serviços, por exemplo, que é muito dependente das pessoas para a entrega da promessa da marca, Christine Vallaster e Leslie de Chernatony (2005) destacaram a dificuldade de transmitir os valores da marca para funcionários de diferentes países com diferentes culturas, ou seja, nesse setor, as diferenças culturais têm um impacto ainda maior.

T. C. Melewar e Christopher Walker (2003) enumeraram os impactos da cultura na gestão das marcas:

1. cores e números têm diferentes significados em diferentes culturas;

2. nomes também podem ter diferentes significados;

3. a noção de tempo varia entre culturas;

4. culturas diferentes têm atitudes diversas em relação a gênero e raça;

5. o papel das pessoas na sociedade pode ser diferente entre culturas;

6. as prioridades das pessoas mudam de acordo com a cultura e com a religião.

Os autores concluíram que as marcas globais sólidas são aquelas capazes de traduzir os valores da corporação em diferentes mercados. Apesar de pregar a adaptação a diferentes culturas, eles consideram que as empresas não devem abrir mão da consistência no posicionamento global das marcas. 
As três principais implicações a serem consideradas na gestão de marcas globais, de acordo com Michael R. Czinkota e llkka A.Ronkainen (2008), são: (a) ressaltar o caráter global da marca, valorizando as características exclusivas das marcas com grande presença global; (b) adotar um posicionamento global (como defendido por outros autores), mas tornar locais certas características da abordagem de marketing; e (c) satisfazer os fundamentos para a construção de marcas sólidas, pois assumir uma abordagem global não é, por si só, garantia de sucesso, podendo, ao contrário, tornar a gestão da marca ainda mais complexa.

Os desafios enfrentados pelas empresas, que desenvolvem estratégias para suas marcas em nível global, dependem do modo como elas se expandiram e da forma como suas operações internacionais são organizadas (Douglas et al., 2001). Empresas como Coca-Cola e Procter \& Gamble se expandiram por meio de suas marcas globais - Coca-Cola, Pampers, Ariel, para citar apenas algumas. No entanto, ao longo do tempo, a estratégia da Coca-Cola, por exemplo, mudou, adquirindo marcas locais ou regionais, como Suco Mais, Matte Leão e Guaraná Jesus (do Maranhão).

Considerando a revisão bibliográfica apresentada, é possível sintetizar que os elementos críticos para a gestão de marcas globais são:

a. Ser uma organização orientada para a marca como recurso estratégico, com foco no longo prazo;

b. construir a marca "de dentro para fora" da organização, mantendo-se fiel aos valores da organização;

c. definir uma estratégia global para a marca desde o seu lançamento;

d. identificar os segmentos-alvo da marca, considerando a seleção de países-alvo e a seleção de segmentos em cada país;

e. definir uma única identidade global para a marca e posicioná-la nos diferentes mercados, de acordo com o contexto e as necessidades de cada mercado;

f. pensar globalmente, mas agir localmente, ou seja, aceitar adaptações, quando necessárias;

g. ser consistente ao longo do tempo e ao redor do mundo;

h. desenvolver um sistema que permita a comunicação entre países e a troca de informações e experiências;

i. contar com um gestor global da marca, que deve desenvolver a estratégia global da marca, assim como alternativas de programas de construção de marcas para serem executados nos diversos países;

j. $\quad$ ter gerentes de marca competentes nos diversos países, capazes de adotar ou adaptar a estratégia global; de contribuir para a equipe global; de executar os programas de construção de marcas, inovando quando possível e/ou necessário; e de comunicar-se com os diversos países onde a marca estiver presente.

\section{PROCEDIMENTO METODOLÓGICO}

Após a revisão bibliográfica, realizou-se uma pesquisa de campo, que compreendeu o levantamento de dados primários. Essa pesquisa teve como objetivos: analisar o processo de construção e de gestão de marcas no âmbito da estratégia de internacionalização e inserção de empresas brasileiras no mundo globalizado. Realizou-se uma pesquisa qualitativa, de caráter exploratório. Segundo Claire Selltiz et al. (1975), um estudo exploratório tem a função, entre outras, de aumentar 0 conhecimento do pesquisador sobre o fenômeno que deseja investigar e de esclarecer conceitos.

Como no presente estudo se visa analisar a construção e a gestão de marcas de empresas brasileiras em processo de internacionalização, o universo pesquisado naturalmente é composto por empresas brasileiras, de capital majoritariamente 
nacional e com sede no Brasil. Essas empresas já devem estar adiantadas em seu processo de internacionalização: devem estar presentes em pelo menos três países, além do Brasil, e ter iniciado o processo de internacionalização há pelo menos cinco anos.

O objeto deste estudo foi o Banco Itaú, que foi escolhido pelas razões explicitadas a seguir.

O setor financeiro no Brasil é altamente lucrativo e os players do setor reconhecem a importância monetária atribuída às marcas, o que os leva a investir constantemente em ações de marketing que reforçam esse ativo intangível como fonte de vantagem competitiva. Marcas como Itaú, Bradesco e Banco do Brasil costumam figurar entras as mais valiosas do Brasil (Manzoni Jr., 2011). A marca Itaú já foi avaliada em 9,6 bilhões de dólares, o que a credenciou a figurar entre as marcas mais valiosas do mundo, alcançando o 90ํlugar no ranking das cem mais, em 2011.

A fusão entre o Unibanco e o Itaú, realizada em novembro de 2008, tornou este último o maior grupo financeiro do hemisfério sul, figurando entre os maiores do mundo em valor de mercado. Um estudo da Price Waterhouse Coopers, de 2011, demonstra que a crise mundial precipitou o destaque dos bancos de países emergentes no contexto internacional. As projeções indicam que, em 2050, os bancos de economias emergentes - Brasil, Rússia, Índia, China, México, Indonésia e Turquia - terão cerca de $50 \%$ dos ativos totais dos bancos (Lima, 2011).

Com isso, estima-se que o sistema financeiro brasileiro aponte duas tendências: a ampliação do número de brasileiros com acesso a serviços bancários e a internacionalização das atividades do setor. Os maiores bancos brasileiros de varejo - Itaú, Bradesco e Banco do Brasil - estão investindo e valorizando a exposição de suas marcas e operações em âmbito internacional. O Itaú, especificamente, intensificou a exploração de mercados externos após a conclusão dos principais processos de integração entre Itaú e Unibanco.

Além da pesquisa de dados secundários, que pode ser relativamente abrangente por ser um setor que está constantemente na mídia e uma marca que é considerada muito valiosa com larga exposição, foi realizada uma entrevista, com duração de cerca de noventa minutos, com o responsável pelo marketing internacional do banco.

Para a coleta de dados, foi utilizada a entrevista em profundidade, a qual tinha por base um roteiro, porque a entrevista é 0 método de coleta de dados fundamental da pesquisa qualitativa (Roesch, 1999; Alves-Mazzotti e Gewandszanajder, 1998). 0 método de comunicação utilizado foi o semiestruturado e não disfarçado.

Como procedimento analítico, adotou-se a análise de conteúdo. Segundo Laurence Bardin (2007), trata-se de um método composto por um conjunto de técnicas de análise de comunicações cujo objetivo é obter indicadores (quantitativos ou não) que permitam a inferência de conhecimentos relativos às condições de produção e recepção das mensagens analisadas. Por meio de procedimentos sistemáticos, chega-se à melhor compreensão da mensagem ou do texto analisado, neste caso, da transcrição das entrevistas realizadas.

A análise dos dados da pesquisa empírica foi iniciada com a pré-análise, conforme sugerido por Bardin (2007), mais especificamente com a preparação do material escolhido, ou seja, com a transcrição da entrevista. Os textos foram sintetizados, eliminando-se repetições e trechos que não seriam relevantes para os objetivos da pesquisa. Foram excluídos os trechos 
iniciais e finais da entrevista (apresentações e saudações), elementos empregados para manter a conversação, elementos ambíguos ou redundantes, comentários sobre outras empresas ou setores que não eram os do entrevistado em questão e trechos que se desviavam dos temas da pesquisa. Os trechos que resultaram dessa preparação foram categorizados segundo os temas, constituindo as categorias, que têm por base os objetivos e a fundamentação teórica da pesquisa. 0 principal critério de categorização foi semântico (categorias temáticas).

\section{ANÁLISE DOS RESULTADOS}

O Itaú é um banco formado por diversas fusões e aquisições, que o transformaram num gigante do setor. No Brasil, ele possuía em 2011 mais de 3.700 agências e quase mil postos de atendimento bancário, além de quase 30 mil caixas eletrônicos. Tinha mais de 100 mil funcionários, em dezenove países, e suas ações são negociadas pelas bolsas de São Paulo, Nova York e Buenos Aires (Itaú, 2011).

0 primeiro passo para a internacionalização se deu com a abertura de uma agência em Buenos Aires, na década de 1980, seguida da compra de uma operação local. 0 entrevistado não soube precisar as motivações para esse primeiro passo, mas afirmou que houve um segundo processo de internacionalização, mais recente e significativo, que começou com a aquisição das operações do Banco de Boston na América Latina (Brasil, Chile e Uruguai), em meados da década de 1990, e posteriormente a fusão com o Unibanco, que tinha operações no Paraguai. Com isso, foi formado o pilar Conesul, que são as cinco operações: Brasil, Uruguai, Paraguai, Argentina e Chile.

Na verdade, o Itaú conta com tipos de operações internacionais distintas. A operação latino-americana, que lida diretamente com o consumidor final, é o foco do presente estudo.

Embora o Itaú esteja se posicionando nos países do hemisfério norte como o "banco latino-americano", não havia uma estratégia a prioride obter essa presença. Segundo o entrevistado, "a gente ainda pensa bastante a nossa operação do Brasil, e do Brasil para o mundo, e a gente não pensa o mundo como um todo". A própria estrutura organizacional evidencia essa situação, pois a área de marketing internacional fica alocada na área de marketing institucional na diretoria de marketing.

Na Argentina, o Itaú iniciou a operação com a abertura de uma agência bancária, mas ganhou relevância apenas após a aquisição de um banco local. 0 modo de entrada foi a aquisição de operações locais, que foram convertidas em Itaú - a marca e a cultura organizacional.

Como as operações latino-americanas são oriundas de aquisições, o Itaú tem públicos-alvo diferentes em cada país. No Chile, por exemplo, como a operação era do Banco de Boston, o público é formado por pessoas de alta renda. Até hoje, as fachadas das agências são cinza, em vez de laranja (cor da marca Itaú no Brasil), porque foi realizada pesquisa e descobriu-se que laranja é a cor de um conhecido varejista local e, portanto, assimilada como mais popular pelos chilenos. Isso mostra que os dirigentes realizam pesquisa junto aos clientes nos mercados locais e ouvem as opiniões dos responsáveis pelas operações locais.

Outra adaptação importante, além da fachada, é o design das agências, que é diferente no Chile e no Uruguai, por exemplo, ao considerar os traços culturais (qual tom de madeira representa solidez, por exemplo) e o que a marca adquirida já representava 
para os clientes locais: "O Itaú tem que ser a mesma pessoa. Talvez ele use roupas diferentes, dependendo de cada país. O Itaú do Brasil certamente não é um cara de terno e gravata. É mais para um cara de bermuda e camisa. (...) No Chile ele seria um cara de terno e gravata, no Uruguai, ele seria um cara talvez não de gravata, mas ia estar de blazer".

No entanto, o entrevistado admite que atualmente o Itaú representa estilos diferentes em cada país e que o caminho é unificar essas identidades, embora o banco dificilmente se torne único em todos os países, até por questões relacionadas à legislação local, como a porta giratória na entrada das agências ou vidros blindados na frente dos caixas.

O slogan "Feito para você" é adotado pelos países latino-americanos com traduções locais.

Nas operações de banco de varejo quase todos os funcionários são locais (mais de 90\%), mas nos escritórios no hemisfério norte, cerca de $60 \%$ dos funcionários são brasileiros, até porque atendem muitos latino-americanos e vendem investimentos nessa região, precisando de conhecimento daqui. Cada unidade latino-americana tem infraestrutura própria, logicamente adequada ao porte da operação, que é muito menor do que a brasileira.

Cada país da América Latina conta com uma equipe de marketing, que desenvolve as estratégias de marketing e executa as atividades localmente, com a aprovação da matriz, a fim de garantir que as ações estejam alinhadas estrategicamente e não venham a ferir algum valor da empresa. Por exemplo, o Itaú tem como norma não patrocinar esportes radicais, que normalmente representam riscos. Além disso, não são admitidas brincadeiras relacionadas ao futebol argentino ou brasileiro, pois, como o Itaú se posiciona como banco latino-americano, não cabe tomar partido nessas rivalidades.

A matriz incentiva a troca de experiências entre as equipes de marketing dos países e procura aproveitar ações realizadas em um país nos demais, quando a ação faz sentido localmente. As operações menores - Paraguai e Uruguai - são incentivadas a testar ações de marketing mais ousadas, que podem ser replicadas nos demais países, pela menor complexidade de implantação em vinte agências, em vez de milhares delas.

Talvez pela grandiosidade da operação brasileira, o entrevistado acredita que muitos funcionários no Brasil desconhecem o fato de o Itaú ter operações de varejo em outros países, mesmo nos escritórios da matriz: "As pessoas não saberiam qual é a diferença do nosso escritório em Dubai, que tem dez pessoas, para o escritório do Chile, que tem 2.000. Então, as pessoas não sabem, têm um pouco do complexo vira-lata do brasileiro. A gente fala: a gente é um banco internacional. Mas, aí, tem muito banco grande aí na frente. A gente é o décimo maior banco do mundo. (...) Até mesmo potenciais futuros funcionários não consideram o Itaú no rol dos bancos internacionalizados, o que o tira da lista daquelas pessoas que almejam carreira internacional".

Diante dessa constatação, a área de marketing internacional decidiu comunicar, tanto externa quanto internamente, a presença internacional do Itaú, com o posicionamento "the global Latin American bank" (o banco global latino-americano). Entretanto, além da desinformação, que pode ser mais rapidamente resolvida, há a necessidade de uma mudança de modelo mental: "A gente não sabe ser matriz. Eu acho que o Brasil é um país adolescente e acho que as empresas do Brasil são empresas adolescentes. (...) Nós tivemos um filho agora, e como eu cuido desse filho? Eu nunca fui pai, eu sempre fui filho. E eu acho que o brasileiro, o Itaú, eu acho que todas as empresas do Brasil sempre foram filhas". 
O registro das marcas institucionais e dos produtos é centralizado na matriz por ser considerado um processo crítico.

Quanto ao composto de marketing, os produtos e preços são definidos localmente, com forte influência da legislação, embora o objetivo do banco seja padronizar produtos. A comunicação e a distribuição (no sentido de design de sites e agências) são adaptadas a cada local, embora haja campanhas institucionais regionais, ou até globais.

\section{CONSIDERAÇÕES FINAIS}

Os resultados da análise mostram que a internacionalização do Itaú é um exemplo rico para analisar os fatores críticos para a construção e a gestão de marcas de empresas brasileiras multinacionais no âmbito da estratégia de internacionalização.

Assim como ocorreu com outras empresas brasileiras, a internacionalização do Itaú não foi motivada pela convicção da necessidade ou da oportunidade da internacionalização, tanto que a operação inicial se deu na Argentina, país próximo psiquicamente, de maneira tímida. Anos depois, foi feita a aquisição de uma operação local para expansão.

Os gestores estão ainda procurando entender quais atributos da identidade da marca devem ser privilegiados nos demais países, quais características da cultura organizacional devem ser impostos ou incentivados nas operações estrangeiras.

Um dos pontos positivos da estratégia de internacionalização do Itaú é a busca do entendimento dos hábitos dos clientes em cada localidade, via pesquisa e funcionários locais, e a compreensão de que a marca ltaú está em patamares diferentes em cada país.

Nas ações de marketing, o Itaú, sem dúvida, age localmente, mas ainda está no processo de pensar globalmente, como marca única e integrada. Inclusive, apesar de ser um dos dez maiores bancos do mundo, ainda é muito pouco conhecido fora da América Latina, o que é um desafio para quem atua num setor onde o conhecimento e a credibilidade da marca são cruciais.

A área de marketing internacional está num momento de repensar a arquitetura das marcas do Itaú, considerando as operações estrangeiras e seus produtos, muitos desenvolvidos localmente, com nomes diferentes. 0 objetivo é padronizar ao máximo os produtos ofertados, especialmente seu nome e características visuais de comunicação, pois a legislação de cada país irá delinear os atributos dos produtos.

Uma vez formadas as bases para a internacionalização, é possível perceber que foram importantes todos os elementos críticos, levantados na revisão bibliográfica, para a gestão da marca no processo de internacionalização.

A pesquisa de campo conduziu a informações relevantes e ajudou a cumprir o objetivo geral do estudo, que foi analisar o processo de construção e gestão de marcas de empresas brasileiras multinacionais no âmbito da estratégia de internacionalização. Neste estudo, procurou-se contribuir para incentivar a mentalidade global do empresariado brasileiro e ampliar a compreensão de que a gestão de marcas é um fator extremamente importante na estratégia de internacionalização de empresas. Sendo o Brasil tradicionalmente um exportador de commodities, produtos sem marca, neste estudo procurou-se mostrar que, por meio da gestão de marcas, as empresas podem competir no exterior com uma oferta diferenciada, de maior valor agregado, reduzindo a dependência da competição com base em preços e custos, o que havia se tornado muito difícil em consequência das características de países como Índia e China. 
É importante, contudo, reconhecer que a abordagem exploratória, o procedimento qualitativo e os métodos aqui adotados possuem uma série de limitações. A seleção de umaúnica empresa não permite generalizar nem chegar a conclusões definitivas. E o método escolhido para a análise dos resultados, a análise de conteúdo, é subjetivo porque depende da interpretação de quem analisa o material.

Neste estudo, procurou-se contribuir para aumentar a participação do Brasil no mundo globalizado, mas há ainda muito a ser feito. 0 estudo será estendido para um número maior de empresas, e os achados serão comparados para enriquecer a pesquisa. Quanto mais experiências de empresas brasileiras que se internacionalizaram forem coletadas, analisadas e divulgadas, maior será o aprendizado para estruturar iniciativas futuras.

Outra sugestão seria realizar pesquisa quantitativa sobre o papel contributivo da gestão de marcas em processos de internacionalização de empresas. Isso poderia ser analisado em universos de empresas brasileiras exportadoras e de empresas brasileiras com investimento externo direto. Este estudo, mais especificamente as experiências do Itaú em relação à gestão de marcas, pode servir de ponto de partida.

\section{REFERÊNCIAS}

AAKER, David A.; JOACHIMSTHALER, Erik. The lure of global branding. Harvard Business Review, Boston, v. 77, n. 6, p. 137-45, nov./dec. 1999.

ALVES-MAZZOTTI, Alda Judith; GEWANDSZNAJDER, Fernando. O método nas ciências naturais e sociais: pesquisa quantitativa e qualitativa. São Paulo: Pioneira, 1998.

BANERJEE, Saikat. Strategic brand-culture fit: a conceptual framework for brand management. Journal of Brand Management, [s. l.], v. 15, n.5, p. 312-321, may 2008.

BARDIN, Laurence. Análise de conteúdo. 4. ed. Lisboa: Edições 70, 2007.

CZINKOTA, Michael R.; RONKAINEN, Ilkka A. Marketing internacional. 8. ed. São Paulo: Cengage Learning, 2008.

DOUGLAS, Susan P. et al. Integrating branding strategy across markets: building international brand architecture. Journal of International Marketing, [s. L.], v. 9, n. 2, p. 97-114, 2001.

GIÃO, Paulo Roberto et al. O processo estratégico de internacionalização da Gerdau. In: SEMINÁRIOS EM ADMINISTRAÇÃO, XI, São Paulo, 2008. Anais... São Paulo: Semead/FEA-USP, 2008.

HATCH, Mary Jo; RUBIN, James. The hermemeutics of branding. Journal of Brand Management, [s. l.], v. 14, n. 1-2, p. 40-59, sep.-nov. 2006.

HOLDEN, Barry. Construindo marcas globais. In: TYBOUT, Alice M.; CALKINS, Tim. (Org.). Branding. São Paulo: Atlas, 2006.

HOLLIS, Nigel. The global brand. New York: Palgrave Macmillan, 2008. 
ITAÚ. Disponível em: <http://itau.com.br>. Acesso em: 16 jun. 2011.

KAPFERER, Jean-Noël. O que vai mudar as marcas. Porto Alegre: Bookman, 2004.

. The post-global brand. Journal of Brand Management, [s. l.], v. 12, n. 5, p. 319-324, june 2005.

LEVITT, Theodore. The globalization of markets. Harvard Business Review, Boston, v. 3, p. 92-102, may/june 1983.

LIMA, A. Ativos: estudo da PWC mostra que crise precipitou ultrapassagem. Jornal Valor Econômico, São Paulo, Caderno de Finanças, 14 jun. 2011.

MANZONI JR., Ralphe. As marcas mais valiosas do Brasil em 2011. IstoÉ Dinheiro, São Paulo, ed. 710, 13 maio 2011.

MATTHIESEN, Insa; PHAU, lan. The 'Hugo Boss' connection: achieving global brand consistency across countries. Journal of Brand Management, [s. l.], v. 12, n. 5, p. 325-338, june 2005.

MELEWAR, T. C.; WALKER, Christopher M. Global corporate brand building: guidelines and case studies. Journal of Brand Management, [s. L.], v. 11, n. 2, p. 157-170, nov. 2003.

MELEWAR, T. C. et al. The influence of culture on brand building in the Chinese market: a brief insight. Journal of Brand Management, [s. L.], v. 11, n.6, p. 449-461, july 2004.

. Danone branding strategy in China. Journal of Brand Management, [s. l.], v. 13, n.6, p. 407-417, july 2006.

RAMSAY, Bill. Whither global branding? The case of food manufacturing. Journal of Brand Management, [s. l.], v. 11, n.1, p. 9-21, sep. 2003.

ROESCH, Sylvia Maria Azevedo. Projetos de estágio e de pesquisa em administração:guia para estágios, trabalhos de conclusão, dissertações e estudos de caso. São Paulo: Atlas, 1999.

SCHUILING, Isabelle; KAPFERER, Jean-Noël. Real differences between local and international brands: strategic implications for international marketers. Journal of International Marketing, [s. l.], v. 12, n. 4, p. 97-112, 2004.

SELLTIZ, Claire et al. Métodos de pesquisa nas relações sociais. São Paulo: EPU, 1975.

TEMPORAL, Paul. Branding in Asia: the creation, development and management of Asian brands for the global market. Singapore: John Wiley \& Sons (Asia) Pte Ltd., 2001.

VALLASTER, Christine; CHERNATONY, Leslie de. Internationalisation of services brands: the role of leadership during the internal brand building process. Journal of Marketing Management, [s. l.], v. 21, p. 181-203, 2005.

VANGELDER, Sicco. The new imperatives for global branding: strategy, creativity and leadership. Journal of Brand Management, [s. l.], v. 12, n. 5, p. 395-404, june 2005. 